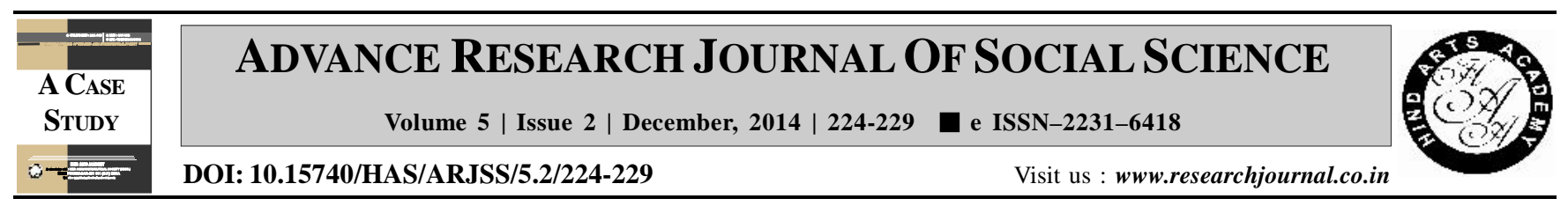

\title{
Constraints faced by tribal women in adoption of organic farming
}

Sonali Sharma* and Snehlata Maheshwari

Department of Home Science Extension and Communication Management, College of Home Science, Maharana Pratap University of Agriculture and Technology, UDAIPUR (RAJASTHAN) INDIA

(Email: sonalicpsharma2010@gmail.com,snehlata2010@gmail.com)

\section{ARTICLE INFO :}

Received

: 04.09 .2014

Accepted

$$
\text { 19.11.2014 }
$$

\section{KEY WORDS :}

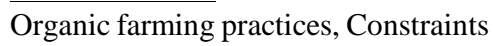

\section{HOW TO CITE THIS ARTICLE :}

Sharma, Sonali and Maheshwari, Snehlata (2014). Constraints faced by tribal women in adoption of organic farming, Adv. Res. J. Soc. Sci., 5 (2) : $224-229$

*Author for correspondence

\section{ABSTRACT}

The objectives of the present research were to study the constraints faced by tribal women in adoption of organic farming. The study was conducted in four villages selected from 150 villages of Jadol, Gogunda and Kotra Panchayat Samities of Udaipur district. The sample consisted of randomly selected 100 respondents from the selected villages namely Kantharia, Jambua, Dhoya and Bansaria. Interview method was used for collecting data from the respondents. Mean per cent score was used for the analysis of data. Findings of the study reveal that, main constraints was personal constraints with the mean weighted score 2.46. Economic constraints were ranked second with MWS 2.30. Technical constraints with overall MWS were found to be 1.88. General constraints were found to be less severe constraints among all other constraints and overall MWS was found to be 1.21. Findings of the study reveal, that majority of the respondents were from 18-30 years of age, all respondents belonged to scheduled caste (tribe) and had farming as their main occupation. Majority of respondents were from nuclear family.
\end{abstract}

